This is an author produced version of a paper published in Scandinavian Journal of Forest Research. This paper has been peer-reviewed and is proof-corrected, but does not include the journal pagination.

Citation for the published paper:

Ringdahl, O., Lindroos, O., Hellström, T., Bergström, D., Athanassiadis, D. \& Nordfjell, T. (2011) Path tracking in forest terrain by an autonomous forwarder. Scandinavian Journal of Forest Research. Volume 26 Number 4, pp 350-359.

http://dx.doi.org/10.1080/02827581.2011.566889

Access to the published version may require journal subscription.

Published with permission from: Taylor \& Francis

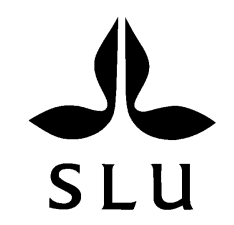

Epsilon Open Archive http://epsilon.slu.se 


\title{
Path tracking in forest terrain by an autonomous forwarder
}

\author{
Ola Ringdahl', Ola Lindroos², Thomas Hellström', Dan Bergström², \\ Dimitris Athanassiadis ${ }^{2} \&$ Tomas Nordfjell ${ }^{2}$ \\ ${ }^{1}$ Dept. of Computing Science, Umeå University, SE-901 87 Umeå, Sweden. \\ ${ }^{2}$ Dept. of Forest Resource Management, Swedish University of Agricultural Sciences, SE-901 83 Umeå
}

Published 2011 in Scandinavian Journal of Forest Research 26(4), 350-359.

The original publication is available at www.tandfonline.com.

\begin{abstract}
Autonomous navigation in forest terrain, where operation paths are rarely straight or flat and obstacles are common, is challenging. This paper evaluates a system designed to autonomously follow previously demonstrated paths in a forest environment without loading/unloading timber, a pre-step in the development of fully autonomous forwarders. The system consisted of a forwarder equipped with a high-precision global positioning system to measure the vehicle's heading and position. A gyro was used to compensate for the influence of the vehicle's roll and pitch. On an ordinary clear-cut forest area with numerous stumps, the vehicle was able to follow two different tracks, three times each at a speed of $1 \mathrm{~m} \mathrm{~s}^{-1}$, with a mean path tracking error of 6 and $7 \mathrm{~cm}$, respectively. The error never exceeded $35 \mathrm{~cm}$, and in $90 \%$ of the observations it was less than 14 and $15 \mathrm{~cm}$, respectively. This accuracy is well within the necessary tolerance for forestry operations. In fact, a human operator would probably have a hard time following the track more accurately. Hence, the developed systems function satisfactorily when using previously demonstrated paths. However, further research on planning new paths in unknown unstructured terrain and on loading/unloading is required before timber transports can be fully automated.
\end{abstract}

Keywords: robotics, autonomous vehicles, automation

\section{Introduction}

Automation of harvesting operations has been applied in many areas of the agricultural sector (e.g. Stoll \& Kutzbach 2000, Pilarski et al. 2002, Pedersen et al. 2006). Starting with the structured and stable greenhouse environment, automation has now successfully moved on to the variable and semistructured outdoor environment that only partly can be tailored to simplify the requirements of robotic systems. Precision is a key issue in navigation of autonomous systems. In agricultural applications a precision of $\pm 0.20 \mathrm{~m}$ has been reported for all kinds of ground conditions (Lenain et al. 2007). Agricultural path tracking addresses, however, mainly straight paths on flat and even, but somewhat soft and slippery grounds (e.g. Pilarski et al. 2002; Tillet et al. 2008; Cariou et al. 2009; Nagasaka et al.
2009). In comparison to agriculture, the forest environment is much more challenging for autonomous machine navigation since operation paths are rarely straight or flat and obstacles are common. In addition the vehicle itself has more problems to move due to high amount of logging residues on the ground surface and sometimes high variability of the soil bearing capacity. Further, the possibility to adapt the environment according to robotic requirements is strongly limited in forestry due to environmental concerns. Forest operations include more complex in-field decisions than typical agricultural operations. Most decisions have to be made in realtime and are often based on experience and prior knowledge (Hellström et al. 2009).

In forestry the forces driving mechanisation and automation are a lack of workers, the amount of hard physical work involved, the aspiration to continue forestry operations year-round and for more hours per day and the desire to reduce costs and the 
lead-times between logging and industrial processing (Sundberg 1978; Silversides 1997). For example, to operate a forwarder in the transportation of round-wood from the harvesting site to the roadside is a monotonous, repetitive hand work with joysticks and buttons. Already in the early days of mechanization it was found that even light, short cycle movements of hands and arms may cause repetitive stress injuries that are characterized by complaints and injuries to the neck, shoulder, arms and cervical spine. Axelsson \& Pontén (1990) point out that about $50 \%$ of the logging machine operators showed more or less serious repetitive strain injury symptoms. Hence, the working conditions would improve if a part of the work operations could be performed autonomously. Moreover, human performance can be limiting work efficiency; for instance, the technical potential is not fully used in many machine movements as humans have difficulties to precisely guide machines or machine parts at high speeds for long periods of time (Pilarski et al. 2002; Hellström et al. 2009). Even though the automation process in forestry is rather slow compared to agriculture, some advances have been made towards a partial or full automation of as well tree harvest as transportation. A machine presented by Golob (1981) autonomously conducted tree felling, delimbing and piling of stems, while robots designed to develop and demonstrate autonomous control were built to perform weeding, pre-commercial thinning and thinning of young coniferous stands (Kourtz 1996). The latter machinery was also used to study forest environment sensing and to test mobility concepts, which also was addressed in the evaluation of an autonomous log skidder that was guided by 6 sonar rangefinders (Anderson et al. 2005). Present research mainly focus on development of support-systems decision management, automation of specific work tasks to relieve the operator from both physical and mental pressure (shared control) and automation of navigation in terrain (Hellström et al. 2009).

Compared to the advanced harvester work with its multitude of operator input in terms of both machine control and active decisions (e.g. Vestlund et al. 2005), work of the forwarder would be feasible to perform autonomously. The key issue is navigation, which requires a real-time knowledge of the current machine position as well as of the coordinates for loading in the forest and unloading at the landing. Moreover, knowledge of how to travel between those points in the most economically and ecologically beneficial way is crucial. A bad choice of route might not just result in excessive time-spending but also in contact with obstacles (trees, stones, holes etc.), which might cause damage to crop trees and the machinery. The presence of a physical path enables navigation by sensors that identify the path (e.g. Andersson et al. 2005; Kise et al. 2005; Søgaard \& Lund 2007; Kim \& Slaughter 2008; Aghkhani \& Abbaspour-Fard 2009;), while virtual paths have to be created and followed in the lack of physical ones. Global positioning systems (GPS) that use satellite signals are commonly employed for virtual paths (e.g. Cariou et al. 2009) and are often combined with path identifying sensors (e.g. Nørremark et al. 2008) as each navigational mode has its advantages and disadvantages (Pilarski et al. 2002). Virtual path-tracking is dependent on a priori information on the environment and the path to follow. Thus, such operation is blind in the sense that it relies on the positional input and the employed map without validating it with the surrounding physical environment. Uninterrupted positional input is thus required, which in the case of GPS-technology is troublesome when working under dense tree canopies (e.g. Naeset et al. 2000; DeCesare 2005). Fortunately for the automation of forwarder work, its desired travel route is roughly known because the harvester has already driven from the road-side to the harvesting site, and manoeuvred at the site when harvesting trees. The harvester has also placed small piles of saw-logs and pulp-wood beside the route it took within the harvesting site. Therefore, before the transportation of $\operatorname{logs}$ begins, it should be possible to acquire information about the route and the positions of wood piles. Moreover, when forwarding at final felling sites there is no tree canopy that might obstruct GPS signals.

Traditional path-tracking algorithms, like Follow the Carrot (Barton 2001) and Pure Pursuit (Coulter 1992), use position information only, and sometimes run into problems such as cutting corners. By taking into account additional information from a human driver during the during a learning phase, the algorithm Follow the Past (Hellström \& Ringdahl 2006), can avoid these problems. This algorithm enabled an autonomous forwarder to follow a previously driven path and avoid unexpected obstacles (Hellström et al. 2006). To ensure accurate navigation despite poor GPS coverage, it was developed to be able to continue to run autonomously even when the GPS signal was lost for short periods of time (Ringdahl \& Hellström 2008). The technique was based on a neural network combining information from a gyro with the forwarder's speed and steering angle. This increased the time the vehicle could run correctly without receiving a GPS position compared to the ordinary odometry system commonly used. On a flat and even open field the machine followed a path demonstrated by an operator with a mean lateral deviation of $\pm 0.1 \mathrm{~m}$, without taking short cuts at 
sharp turns (Hellström et al. 2009). To work satisfactory on uneven forest terrain, the path tracking algorithm must be able to compensate for the vehicle slipping and sliding in the rough terrain. Furthermore, driving in slopes and over large stumps may cause errors in the position estimates due to displacement of the GPS antennas. A brief survey of more path-tracking control algorithms can be found in (Mäkelä 2001).

The present study aims at evaluating the path tracking capability of an autonomous forwarder in a real forest environment, and compare the results with previous tests on flat and even ground.

\section{MATERIALS AND METHODS}

\section{Vehicle and path tracking equipment}

The trial vehicle was a 10 tonnes Valmet 830 forwarder (Fig. 1). The vehicle consisted of two parts joined through articulated steering with double acting cylinders. The maximum steering angle was $43^{\circ}$. The front part comprised cab, engine, main hydraulic system, front bogie axle and hydraulic and fuel tanks. The rear part comprised the bunk area and the rear bogie axle. The forwarder had an 8 -wheel drive hydrostat-mechanic transmission. For more details about the vehicle, see Hellström et al. (2009). For positioning of the vehicle, a Javad Maxor Real-Time Kinematic Differential GPS (RTK DGPS) system with three receivers was used. This system has a much higher accuracy than regular GPS receivers (in the order of $\pm 2 \mathrm{~cm}$ with clear views of at least four or five satellites). One reason for the improved accuracy is the use of a reference station, which is a stationary GPS receiver (Differential GPS: DGPS) able to send correction data to the two mobile receivers. Another reason is the basic measuring technique Real-Time Kinematics (RTK), in which the carrier wave of the signal received from the GPS satellites is used. The carrier wave has a relatively short wavelength, enabling more accurate position estimates (Zhao 1997). One advantage with the used GPS model is its compatibility with both the Russian GLONASS system and the American GPS system. This provided an important backup and also increased the accuracy; especially on the high latitudes (64 degrees north) where the tests described here were conducted. The GPS position was available during the entire test, so no other positioning system had to be used.

In addition to position, the GPS system also accurately measured the vehicle's heading. The heading was calculated by comparing the position of two GPS antennas mounted next to each other at approximately $1.2 \mathrm{~m}$ distance. The antennas were placed on the roof of the forest machine $3.77 \mathrm{~m}$ above ground level. The reported position and heading referred to this point while the path-tracking algorithm needed coordinates at ground level. A coordinate transformation was therefore necessary and for this the vehicle's roll and pitch had to be taken into account. The AHRS 400CC gyro (Crossbow Inc., U.S.A) was used to measure these angles dynamically with an accuracy of approximately \pm 2 degrees. The angles were then used to calculate the position of a reference point, located at ground level below the centre of the front part of the vehicle. Ground level was defined as being $3.77 \mathrm{~m}$ below the position given by the GPS. In order to determine the steering angle the forwarder was equipped with a sensor in the hydraulic cylinders controlling the articulation link. An extensive software system comprising more than 50000 lines of source code was developed to implement the necessary functionality (Hellström et al. 2008). An overview of the hardware used in the tests can be seen in Figure 2.

The operator initiated and supervised the autonomous machine through a laptop. In addition to user interface, this laptop contained high-level routines for path tracking and functions for learning a new path. Data recorded from various sensors on the autonomous machine was collected here. On the vehicle, the hardware was placed on the roof and in the cabin. A mobile computer responsible for lowlevel control and data analysis was placed in the cabin. The forest machine was interfaced via its Vehicle Control Unit which was connected to our system through a device converting signals from the vehicle's CAN bus to Ethernet (and vice versa). Control signals for requested speed and steering angles were transmitted to the vehicle and the current speed and steering angle were reported back to the system. The Ethernet switch connected the equipment in the cabin to the equipment on the roof. Gyro and GPS provided data in RS232 format and were therefore converted to Ethernet format. The RTK Differential GPS (RTK-DGPS) system was connected to the two GPS antennas on the vehicle and a radio antenna for communication with the DGPS reference station placed on the ground in close proximity to the path, see Figure 2. The hardware on the forest machine communicated with the operator laptop via Wireless LAN. The previously developed path-tracking algorithm Follow the Past (Hellström \& Ringdahl 2006) was responsible for keeping the vehicle on the previously demonstrated path. The algorithm consisted of three separate subfunctions suggesting one steering command each, which were then fused together.. The first subfunction imitated the steering angles that the driver used during the learning phase. The second sub- 
function aimed at turning the vehicle to the same direction as during the learning phase. The last subfunction turned towards the route if the machine was located beside it. In this study the algorithm was improved by tuning the quickness that the vehicle returned to the path. If it returns too slowly the pathtracking errors will become larger. If the vehicle returns too fast, it risks oscillating around the path.

\section{Stand and track data}

The study was performed $10 \mathrm{~km}$ west of Umeå in Northern Sweden (63.78 N, 20.07 E) during a two day period in December 2008. The forest stand was situated $45 \mathrm{~m}$ above sea level in an area dominated by coarse textured sandy till soil and with no visible ground water. Just days before the study the stand had been harvested (final felling by clear cutting). In addition to roundwood, logging residues (tops and branches) were to be recovered for bioenergy and had therefore been piled. The area contained circa 1000 fresh stumps per ha with a mean diameter of circa $28 \mathrm{~cm}$ in addition but there were very little loose tree parts on the ground.

Two tracks were selected on the clear cut area. Track 1 (Fig. 3, left pane) had a length of $74 \mathrm{~m}$ and was oriented in the same direction as the main slope of the almost level terrain. The track's orientation in the terrain resulted in elevation differences equal to a downhill slope of in average 2.3 degrees during the first $50 \mathrm{~m}$ and the remaining distance on level ground. The vertical difference was $2 \mathrm{~m}$. Track 2 (Fig. 3, right pane) had a length of $85 \mathrm{~m}$, and its almost circular orientation made the vehicle travel down, parallel, and up the main slope direction (north-east). The main slope was 5.3 degrees and the track's orientation resulted in elevation differences equal to a downhill slope of in average 3.7 degrees during the first $40 \mathrm{~m}$ and an uphill slope of in average 3.9 degrees at the remaining part. The vertical difference between the lowest and highest part of the track was $3 \mathrm{~m}$. Side slope and obstacles (stumps) together gave the forwarder an inclination of maximum 7-8 degrees for both tracks during short periods. The forwarder had a side inclination of more than 2.5 degrees during $5 \%$ of the distance on track 1 and $30 \%$ of the distance on track 2 . There was no ground frost or snow cover during the test, only a thin layer of rime on the ground surface. During the study the temperature was circa $0^{\circ} \mathrm{C}$ and no precipitation occurred.

Stump heights and diameters varied between $14-$ $43 \mathrm{~cm}$ and $11-49 \mathrm{~cm}$, respectively, for the two tracks (Table 1). In average the machine passed over a stump every $3-5 \mathrm{~m}$ of driving distance. In track $1,60 \%$ of the stumps were passed over by the left side of wheel pairs, while equally many stumps were passed over by each side of wheel pairs in track 2 .

On both tracks the forwarder performed the first run (reference run) driven by an operator. Thereafter the same path was driven three times autonomously by the path-tracking algorithm while measuring the lateral distance to the reference path (path-tracking errors) with the GPS at $5 \mathrm{~Hz}$ intervals (approximately each 0.25 to $0.30 \mathrm{~m}$ ). In addition, manual measurements were obtained by marking the ground at the left rear tire of the forest machine at circa $4 \mathrm{~m}$ intervals during each run and then measuring the lateral distance between the reference path and the new run with a measuring tape. Since the GPS antennas were placed on the roof of the machine, they moved considerably sideways when going in rough terrain, resulting in an incorrect estimate of the forest machine position. The reason for doing manual measurements was to verify that the technique to compensate for this error worked as well as expected. In previous studies path tracking errors have been reported either as absolute mean values (e.g. Aghkhani \& Abbaspour-Fard 2009) or as root mean square errors (e.g. Nagasaka et al. 2009). For comparability, these two formats as well as the standard deviation (SD) and distribution of the absolute mean were calculated individually for the GPS and manual measurements.

\section{RESULTS}

For the three runs of the first track, the mean absolute lateral deviation from the reference run was $0.07 \mathrm{~m}$ according to the GPS, and $0.06 \mathrm{~m}$ according to the manual measurements (Table 2; Fig. 4). The maximum deviations were $0.35 \mathrm{~m}$ and $0.20 \mathrm{~m}$ according to the GPS and the manual measurements, respectively (Fig. 4). The large deviations in the beginning of the runs that can be seen in Figure 4 are due to difficulties in placing the vehicle at exactly the same starting position as the reference track. For the second track the mean absolute lateral deviation from the reference run was $0.06 \mathrm{~m}$ according to the GPS and $0.05 \mathrm{~m}$ according to the manual measurements (Table 2; Fig. 5). The maximum deviations were $0.28 \mathrm{~m}$ and $0.19 \mathrm{~m}$ according to the GPS and the manual measurements, respectively (Fig. 5). According to the GPS measurements, 90\% of the path-tracking errors were less than $15 \mathrm{~cm}$ in track 1 and $14 \mathrm{~cm}$ in track 2 .

Manually recorded travel time for the reference run was $68.7 \mathrm{~s}$ for track 1 and $83.9 \mathrm{~s}$ for track 2 , resulting in average speeds of 1.08 and $1.05 \mathrm{~m} \mathrm{~s}^{-1}$, respectively. When autonomously tracking the path, the corresponding manually recorded mean speeds per run were 1.11 (SD 0.01) in track 1 and 1.05 (SD 
0.01) $\mathrm{m} \mathrm{s}^{-1}$ in track 2. Compared to the reference run, the path tracking speed was slightly higher $\left(0.02 \mathrm{~m} \mathrm{~s}^{-1}\right)$ in track 1 (d.f. $\left.=2, \mathrm{~T}=13.77, \mathrm{p}=0.005\right)$ and equal in track 2 (d.f. $=2, \mathrm{~T}=-0.83, \mathrm{p}=0.493)$.

\section{DISCUSSION}

Our results show that it is possible to modify a conventional forwarder so it is able to autonomously follow a previously demonstrated path with high accuracy, even in a normal Scandinavian forest environment. In fact, lateral path tracking errors were similar to many errors reported when autonomously following paths in agricultural conditions (Lenain et al. 2007; Zhu et al. 2007; Nagasaka et al. 2009). Surprisingly, the path tracking errors were generally smaller in the present study compared to when the same system was tested on flat and even ground (Hellström et al. 2009). One plausible explanation is that the Path-tracking algorithm was better tuned in the present study and some of the software functions supporting path tracking have been further developed and optimized since the previous study. Path tracking errors were generally similar over runs, indicating that the errors were systematic and not random (Figs. $4 \& 5$ ). The lateral path tracking errors from the two different measuring methods (manually and GPS) were also quite similar, indicating that the systematic errors were not due to low accuracy in GPS signals (e.g. positioning errors when demonstrating the path to follow). Concordance between manual and GPS observations also indicate that the technique to minimize the negative effect of vehicle roll and pitch on GPS position worked well. Periodically changed lateral errors have previously been observed when using RTKGPS for path tracking (Kise et al. 2005) and were then suggested to be caused by the non-linearity of the steering system and/or poor performance of the steering controller. This seems to be the probable cause also in this study. The forest machine's steering response is slow, such that it can take several seconds for the machine to reach a new required steering angle. This may cause the algorithm to overcompensate the steering angle, leading to the vehicle oscillating around the path. To avoid this, some parameters in the path tracking algorithm can be tuned. However, this tuning is a trade-off between quickly returning to the reference path and avoiding the oscillating behavior. Figures $4 \& 5$ suggest that the deviation could depend on how much the vehicle steers. However, no significant relation could be found between path deviation and steering angle when analyzing them graphically. Another possible source for positional errors is the accuracy of the gyro. Due to the GPS antennas' placement almost $4 \mathrm{~m}$ above ground level, driving over a $40 \mathrm{~cm}$ high stump will cause the vehicle to roll almost $9^{\circ}$ and the GPS antennas to move $58 \mathrm{~cm}$ to the side. The gyro is used to compensate for this effect, but its reported $\pm 2^{\circ}$ accuracy corresponds to $\pm 13 \mathrm{~cm}$ positional error in this case. However, in the recorded data, path deviation has no significant relation to roll according to graphical analyses. This shows that the error in measured roll is random and only results in increased positional noise. The observed noise in path deviation is in the order of \pm 2.5 cm (cf. Figs. $4 \& 5$ ) and can be partly caused by this inaccuracy in roll measurements. Another cause for the noise could be discrepancies in timing between position readings from the GPS and roll readings from the gyro.

In the study the forwarder operated at an average speed of $1 \mathrm{~m} \mathrm{~s}^{-1}$, which is very close to the one expected in real work situations (Nordfjell et al. 2003). The study gave no indications that deviations would increase substantially with increased speed. Accurate path tracking is thus probably technically possible at higher speeds with an autonomous forwarder. In conventional forwarders, however, increased speed would result in a poor operator environment due to whole body vibrations (Rehn et al. 2005).

Concerning the two methods for measuring path tracking errors (GPS and manually) it should be noted that the path tracking algorithm works with positions given by the GPS and transformed to a point at ground level below the centre of the front part of the vehicle. The path tracking errors reported by the GPS refer to the deviation for this point. The manual measurements, on the other hand, refer to the rear part of the vehicle. Due to the articulated joint architecture, these two errors are not necessarily the same. However, the study indicates that the two ways of measuring path deviations give similar results.

In precision agriculture, navigational errors in the order of millimetres are both required and feasible (e.g. Belforte et al. 2006; Søgaard \& Lund 2007; Kim \& Slaughter 2008; Tillett et al. 2008; Nagasaka et al. 2009). In a forest environment such a high accuracy is unfeasible due to the many obstacles and changes in surface characteristics. Thus, the vehicle can slip sideways from an obstacle even if the correct path is followed, as was also observed during the study. Furthermore, requiring such high accuracy would lead to unacceptably many corrections in steering angle. On the other hand, the need for path-tracking precision in forwarding might not be as high as in many agricultural operations. Whereas agricultural crop densities often require centimeter and even millimeter precisions, the distance between Scandinavian crop trees is typically $2 \mathrm{~m}$ 
(2500 trees $\left.\mathrm{ha}^{-1}\right)$ in planting and 3-5 $\mathrm{m} \mathrm{(500-1000}$ trees $\mathrm{ha}^{-1}$ ) in final felling. We estimate that the precision in the presented work (errors $<0.3 \mathrm{~m}$ ) is enough for safe navigation of an autonomous vehicle when performing forestry operations. In fact, it would probably be difficult for professional human operators having better path tracking accuracy than the autonomous machine had in this study. A GPS system, such as the one used in the presented work, delivers more than sufficient positioning accuracy if signals from sufficiently many satellites can be received. However, a fully autonomous system operating in forest environment must be equipped with additional positioning systems to complement GPS if the satellite signals are occluded. Suitable choices are Inertial Navigational Systems (INS) or systems based on visual odometry. In a real-life application, the path-tracking algorithm described here would have to be combined with a system for avoiding obstacles such as trees or human beings (Hellström \& Ringdahl 2009).

In the future we will challenge the studied system with additional conditions normally found in the forest work environment. In boreal forests forestry machinery must be able to function under tree canopy (with bad GPS coverage), in slippery slopes, in snow and in temperatures far below $0^{\circ} \mathrm{C}$. Moreover, it is essential to evaluate the system's performance when carrying out its actual work; to transport logs. With the basic functionality of system granted, vehicle load and its effect on vehicle dynamics will be evaluated. The ultimate aim of future studies would be to contribute in the development of a forwarder that is not dependent on initial operator guidance to find its path. Information from a priori maps is a possible solution and could be created in simulations (Hellström \& Ringdahl 2009). This makes the task a bit easier compared to navigating in unknown unstructured areas. However, using information from the harvester would be a more desirable solution since it always has travelled the area before the forwarder. Knowing where the harvester has driven and where it left the log piles, a system planning which route the forwarder should take to pick up the piles can be developed (e.g. Flisberg et al. 2007). Even with this kind of planning software, a method to guide the vehicle along the planned path, like the one presented in this paper, is still required.

\section{Acknowledgements}

Alberto Gappmayer Biscaia is thanked for substantial contributions in the field test. The study was financed by Kempe foundation, VINNOVA and the Swedish University of Agricultural Sciences.
Thanks to Komatsu Forest for providing a forest machine.

\section{References}

Aghkhani, M.H. \& Abbaspour-Fard, M.H. (2009). Automatic off-road vehicle steering system with a surface laid cable: Concept and preliminary tests. Biosystems Engineering, 103, 265-270.

Anderson, I.P., Carlson, A.C., Edwards, B.D., Anderson, M.J. \& Feeley, J.J. (2005). An autonomous forest robot that uses a hierarchical fuzzy logic controller. Transactions of the ASAE, 48(4), 1603-1617.

Axelsson, S-Å. \& Pontén, B. (1990). New ergonomic problems in mechanized logging operations. International Journal of Industrial Ergonomics, 5, 267-273.

Barton, M.J. (2001). Controller Development and Implementation for Path Planning and Following in an Autonomous Urban Vehicle. Undergraduate thesis, University of Sydney, November.

Belforte, G., Deboli, R., Gay, P., Piccarolo P. \& Ricauda Aimonino, D. (2006). Robot design and testing for greenhouse applications. Biosystems Engineering, 95 (3), 309-321.

Cariou, C., Lenain, R., Thuiot, B. \& Berducat, M. (2009). Automatic guidance of a four-wheel-steering mobile robot for accurate field operations. Journal of Field Robotics, 26(6-7), 504-518.

Coulter, R.C. (1992) . Implementation of the pure pursuit path tracking algorithm, Technical Report CMU-RITR-92-01, Robotics Institute, Carnegie Mellon University, Pittsburgh, PA.

DeCesare, N. J., Squires, J. R. \& Kolbe, J. A. (2005). Effect of forest canopy on GPS-based movement data. Wildlife Society Bulletin, 33(3), 935 -941.

Flisberg, F., Forsberg, M. \& Rönnqvist, M. (2007). Optimization based planning tools for routing of forwarders at harvest areas. Canadian Journal of Forest Research, 37, 2153-2163.

Golob, T.B. (1981). Worker and his tools. Seminar on Occupational Health \& Safety and Applied Ergonomics on Highly Mechanised Logging operations. FAO/ECE/ILO, Ottawa, Canada.

Hellström, T., Johansson, T. \& Ringdahl, O. (2006). Development of an autonomous forest machine for path tracking. Springer Tracts in Advanced Robotics, 25, 603-614.

Hellström, T., Johansson, T. \& Ringdahl, O. (2008). A Java-based middleware for control and sensing in mobile robotics. In S.I. Ao, C. Douglas, W.S. Grundfest, L. Schruben \& J. Burgstone (Eds.). International Conference on Intelligent Automation and Robotics 2008 (pp. 649-654). San Francisco: IAENG,

Hellström, T., Lärkeryd, P., Nordfjell, T. \& Ringdahl, O. (2009). Autonomous forest vehicles -envisioned and state of the art. International Journal of Forest Engineering, 20(1), 31-38.

Hellström, T. \& Ringdahl, O. (2006). Follow the Past: a path-tracking algorithm for autonomous vehicles. International Journal of Vehicle Autonomous Systems, 4 (2-4), 216-224. 
Hellström, T. \& Ringdahl, O. (2009). Real-time path planning using a simulator-in-the-loop. International Journal of Vehicle Autonomous Systems, 7(1-2), 5672.

Kim, D.H. \& Slaughter, D.C. (2008). Image based realtime displacement measurement system. Biosystems Engineering, 101(4), 388-395.

Kise, M., Zhang, Q. \& Rovira Más, F. (2005). A stereovision based crop cow detection method för tractorautomated guidance. Biosystems Engineering, 90(4), 357-367.

Kourtz, P. (1996). Autonomous forestry robots for brushing and thinning in young conifer stands: early Canadian experiences. In: S. Gellerstedt, C. Asplund \& I. Wästerlund (Eds.). Robotics with application to forestry. Uppsatser och Resultat nr. 285. Department of Operational Efficiency, SLU, Garpenberg, Sweden. ISSN: 0282-2377.

Lenain, R., Thuilot, B., Cariou, C. \& Martinet, P. (2007). Adaptive and predictive path tracking control for offroad mobile robots. European Journal of Control, 134, 419-439.

Mäkelä, H. (2001). Outdoor Navigation of Mobile Robots. $\mathrm{PhD}$ thesis, Helsinki University of Technology, 2001.

Naesset, E.; Bjerke, T.; Bvstedal, O. \& Ryan, L. (2000). Contributions of differential GPS and GLONASS observations to point accuracy under forest canopies. Photogrammetric engineering and remote sensing, 66(4), 403-407.

Nagasaka, Y., Saito, H., Tamaki, K., Seki, M., Kobayashi, K. \& Tanawaki, K. (2009). An autonomous rice transplanter guided by global positioning system and enertial measurement unit. Journal of Field Robotics, 26(6-7), 537-548.

Nordfjell, T., Athanassiadis, D. \& Talbot, B. (2003). Fuel consumption in forwarders. International Journal of Forest Engineering, 14(2), 11-20.

Nørremark, M., Griepentrog, H.W., Nielsen, J. \& Søgaard, H.T. 2008. The development and assessment of the accuracy of an autonomous GPS based system for intra-row mechanical weed control in row crops. Biosystems Engineering, 101(4), 396-410.

Pedersen, S. M., Fountas, S., Have, H. \& Blackmore, B. S. (2006). Agricultural robots - system analysis and economic feasibility. Precision Agriculture, 7, 295308.

Pilarski, T., Happold. M., Pangels, H., Ollis. M., Fitzpatrick, K. \& Stentz, A. (2002). The Demeter System for Automated Harvesting. Autonomous Robots, 13, 9-20.

Rehn, B., Lundström, R., Nilsson, L., Liljelind, I. \& Järvholm, B. (2005). Variation in exposure to wholebody vibration for operators of forwarder vehicles aspects on measurement strategies and prevention. International Journal of Industrial Ergonomics, 35, 831842.

Ringdahl, O. \& Hellström, T. (2008). Autonomous Forest Machines - Techniques and Algorithms for Unmanned Vehicles. ( $1^{\text {st }}$ ed.). Saarbrücken: VDM Verlag Dr. Müller.

Silversides, C.R. (1997). Broadaxe to flying shear. The mechanization of forest harvesting east of the Rockies. Transformation series 6. National museum of science and technology. Ottawa, Canada.

Søgaard, H.T. \& Lund, I. (2007). Application accuracy of a machine vision-controlled robotic micro dosing system. Biosystems Engineering, 96(3), 315-322.

Stoll, A. \& Kutzbach, H.D. 2000. Guidance of a Forage Harvester with GPS. Precision Agriculture, 2 (3), 281291.

Sundberg, U. (1978). Teknik i skog. [Technology in the forest]. In J. Fries \& J. Zimmerman (Eds.). Skogshögskolan 150 år. Problem och idéer i svenskt skogsbruk 1828-1978. [The Royal College of Forestry 150 years. Problems and ideas in Swedish forestry 1828-1978]. Stockholm: Liber (In Swedish).

Tillet, N.D., Hague, T., Grundy, A.C. \& Dedousis, A.P. (2008). Mechanical within-row weed control for transplanted crops using computer vision. Biosystems Engineering, 99(2), 171-178.

Vestlund, K., Nordfjell, T. \& Eliasson, L. (2005). Comparison of Human and Computer-based Selective Cleaning. Silva Fennica, 39(4), 509-523.

Zhao, Y. 1997. Vehicle Location and Navigation Systems. $\left(1^{\text {st }}\right.$ ed.). Norwood: Artech House publishers.

Zhu, Z., Jun, C., Toyofumi, Y., Ryo, T., Zheng-he, S. \& En-rong, M. 2007. Path tracking control of autonomous agricultural mobile robots. Journal of Zhejiang University - Science A, 8(10), 1596-1603. 
Figures and tables

Table 1. Characteristics of stumps that wheels rolled over

\begin{tabular}{|c|c|c|c|c|c|c|c|}
\hline & \multicolumn{4}{|c|}{ Diameter (m) } & \multicolumn{3}{|c|}{ Height (m) } \\
\hline & $\mathrm{N}$ & Mean & SD & Min-max & Mean & SD & Min-max \\
\hline Path 1 & 25 & 0.27 & 0.10 & $0.12-0.43$ & 0.27 & 0.08 & $0.14-0.39$ \\
\hline Path 2 & 18 & 0.29 & 0.10 & $0.11-0.49$ & 0.26 & 0.08 & $0.15-0.43$ \\
\hline
\end{tabular}

Table 2. Lateral deviations from the reference path presented as means and standard deviations (SD) of absolute values and as root mean square errors (RMSE) in meters presented according to the manual measurements and the GPS measurements. $\mathrm{n}$ is the number of measurements

\begin{tabular}{|c|c|c|c|c|c|c|c|c|c|}
\hline \multirow[b]{3}{*}{ Track } & \multirow[b]{3}{*}{ Run } & \multicolumn{3}{|c|}{ Manual measure- } & \multicolumn{5}{|c|}{ GPS measure- } \\
\hline & & \multicolumn{3}{|c|}{ ment } & \multicolumn{5}{|c|}{ ment } \\
\hline & & $\mathrm{n}$ & Mean & SD & RMSE & $\mathrm{n}$ & Mean & SD & RMSE \\
\hline \multirow[t]{4}{*}{1} & 1 & 18 & 0.06 & 0.07 & 0.09 & 321 & 0.08 & 0.06 & 0.10 \\
\hline & 2 & 18 & 0.06 & 0.06 & 0.08 & 316 & 0.07 & 0.06 & 0.10 \\
\hline & 3 & 18 & 0.06 & 0.06 & 0.09 & 321 & 0.07 & 0.05 & 0.09 \\
\hline & Mean & 54 & 0.06 & 0.06 & 0.09 & 958 & 0.07 & 0.06 & 0.09 \\
\hline \multirow[t]{4}{*}{2} & 1 & 21 & 0.05 & 0.04 & 0.07 & 342 & 0.05 & 0.04 & 0.06 \\
\hline & 2 & 21 & 0.04 & 0.05 & 0.07 & 322 & 0.06 & 0.05 & 0.08 \\
\hline & 3 & 21 & 0.05 & 0.04 & 0.07 & 320 & 0.07 & 0.06 & 0.09 \\
\hline & Mean & 63 & 0.05 & 0.05 & 0.07 & 984 & 0.06 & 0.05 & 0.08 \\
\hline
\end{tabular}




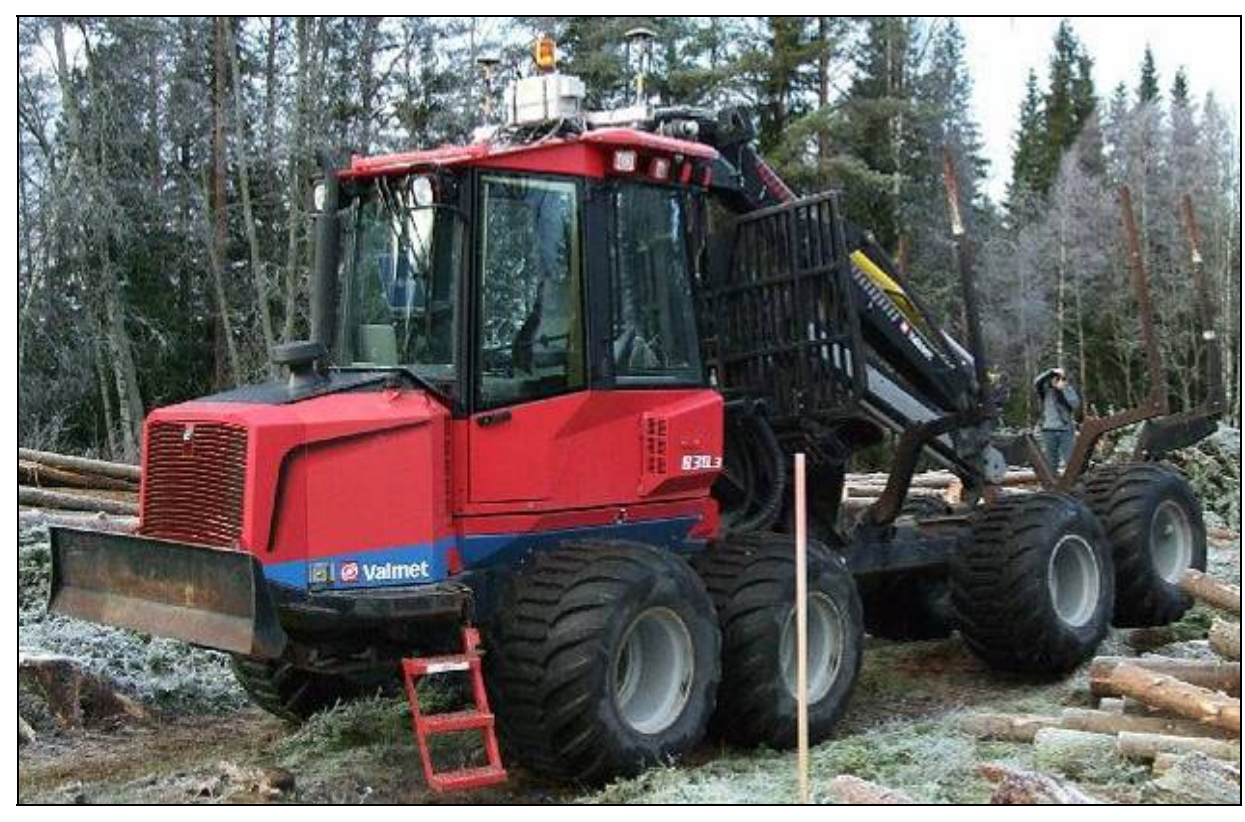

Figure 1. The studied Valmet 830 forwarder equipped with an RTK DGPS for localization and heading meaurements and a gyro determining the vehicle's roll and pitch angles. Photo: Ola Ringdahl.

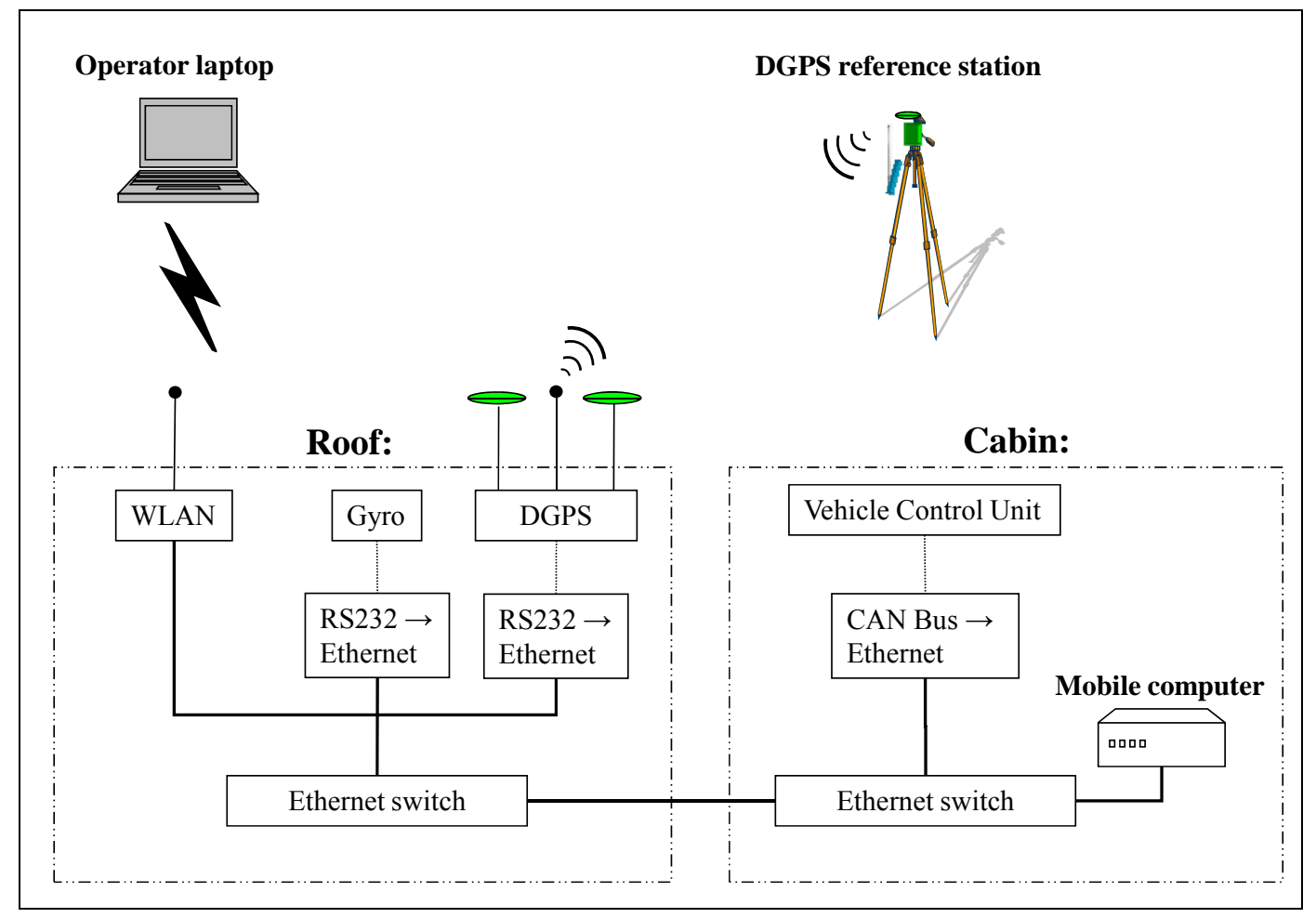

Figure 2. Block scheme of hardware for the autonomous forest vehicle used in the presented experiments. The DGPS reference station was placed on the ground nearby the forest machine. 

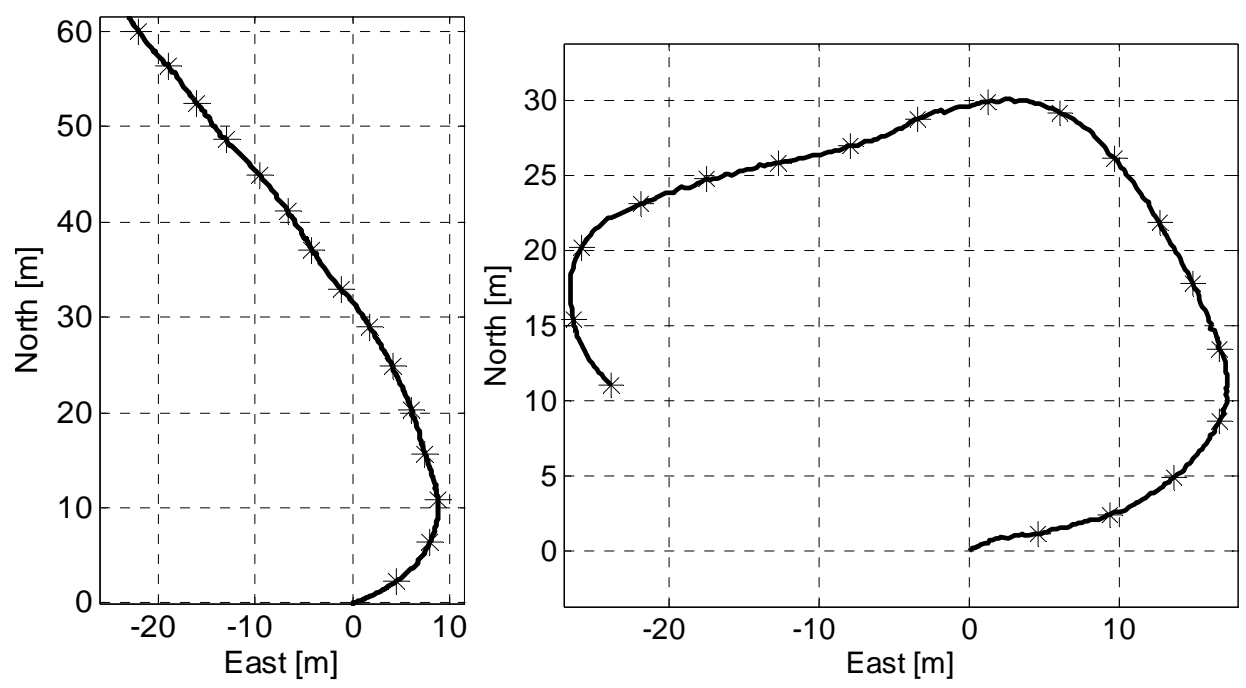

Figure 3. Trajectories of reference paths 1 (left pane) and 2 (right pane). The vehicle started at position $(0,0)$, i.e. in the lower part of the figure. The paths were, respectively, 74 and 85 metres long. Every fifth meter of the paths is marked with $a^{*}$. 


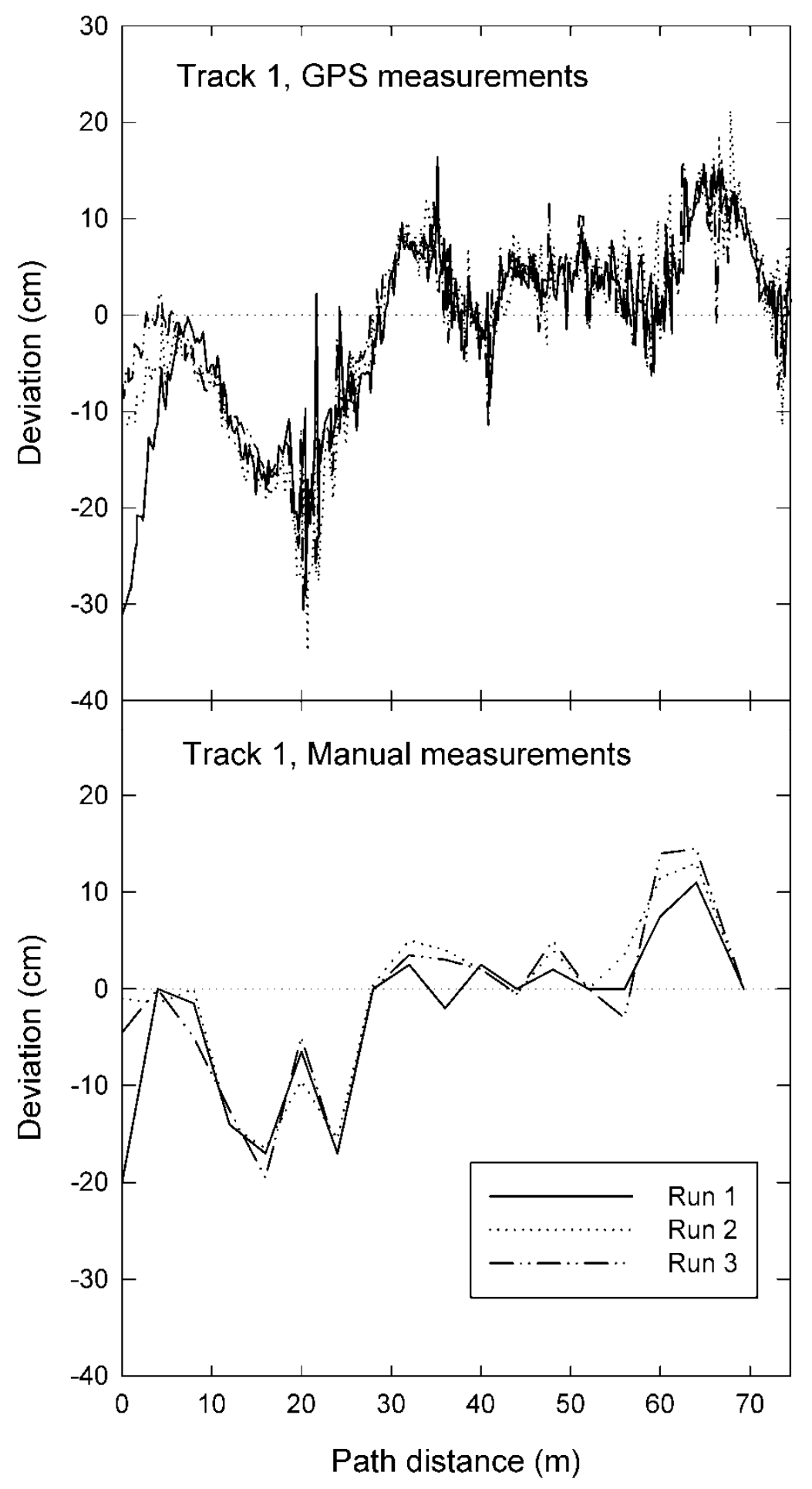

Figure 4. Lateral path tracking deviations from the reference path in track 1 measured with a GPS and manually. Negative and positive values indicate deviations to the left and to the right, respectively, of the reference path. Measurements were taken at the same path distances, but path length differed since the GPS and the manual measurements were recorded in the front and in the rear of the vehicle, respectively. The large deviations in the beginning are due to the machine not being placed exactly on the same starting position as the reference track. 


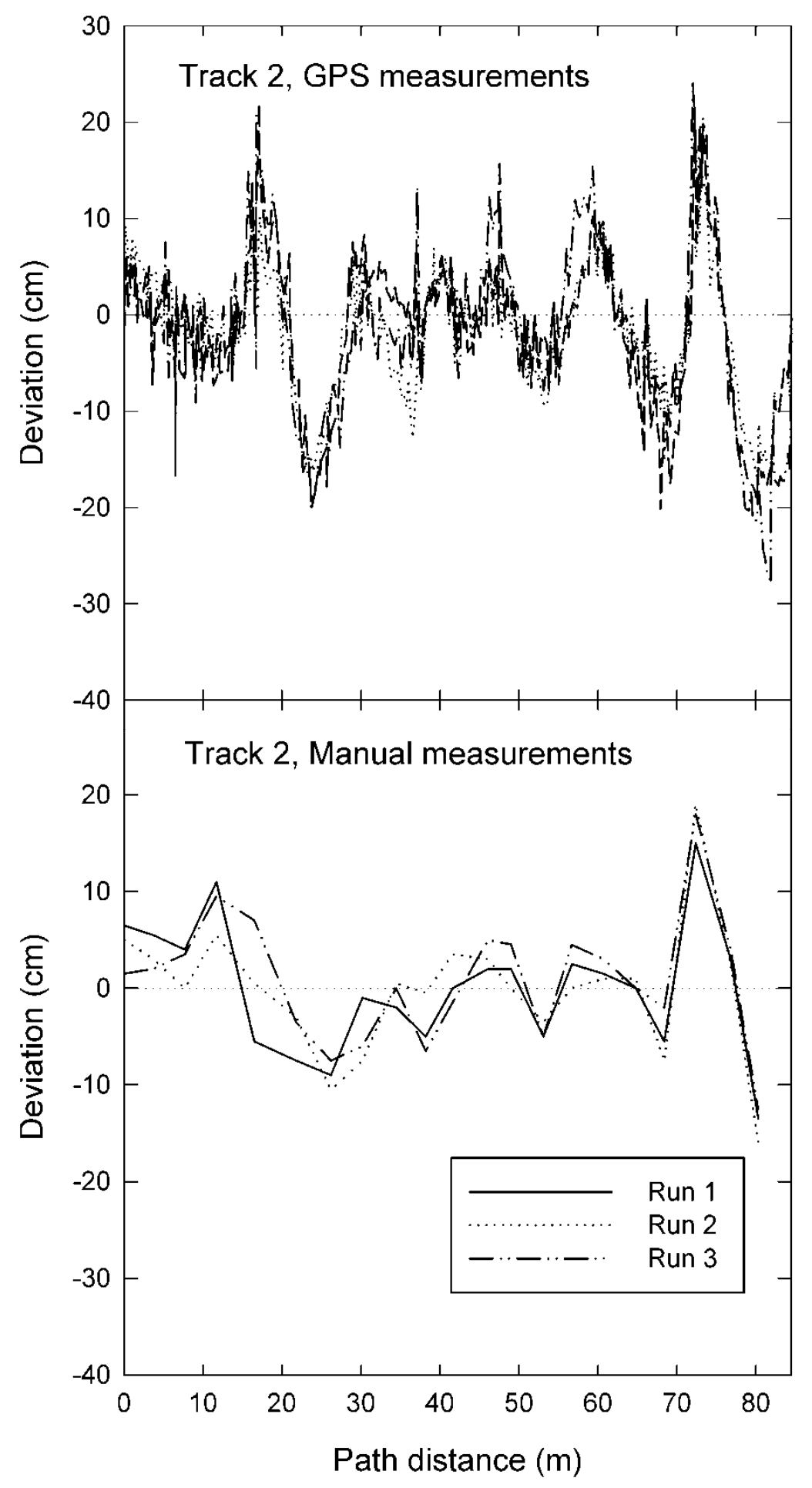

Figure 5. Lateral path tracking deviations from the reference path in track 2 measured with a GPS and manally. Negative and positive values indicate deviations to the left and to the right, respectively, of the reference path. Measurements were taken at the same path distances, but path length differed since the GPS and the manual measurements were recorded in the front and in the rear of the vehicle, respectively. 